\author{
Educational Research for Social Change (ERSC) \\ Volume 8 No. 1, April 2019
}

pp. 120-137

ersc.nmmu.ac.za

ISSN: 2221-4070

\title{
Hawks, Robots, and Chalkings: Unexpected Object Encounters During Walking Interviews on a College Campus
}

\author{
Maureen A. Flint \\ The University of Georgia \\ flintmaureen@gmail.com
}

\begin{abstract}
A feeding hawk, a sculpture of a fallen robot, and chalk markings pointing to a slave cemetery-each of these objects was unexpectedly encountered during walking interviews on a college campus. This article explores these object encounters in turn as provocations toward the potential for walking as a method to generate interventions in the reproduction of hegemonic spaces. Specifically, this paper takes up the Deleuzoguattarian concepts of the rhizome and the assemblage to explore how the practice of walking makes possible creative and imaginative explorations in the relationship between objects and place. Methodologically, walking produces the possibility for affirmative difference in the interview, a positive embrace of reading objects as complex and connected through an embodied enactment of rhizomes and assemblages. Inquiry that thinks with rhizomes and assemblages connects disparate encounters, moments, and objects through affirmative difference, embracing connections and relations. This article suggests implications for how the walking interview might engender reflective entanglements of theory and methodology, resist extractive methods, as well as produce imaginative reconceptualisations of place, and interventions and disruptions of hegemonic narratives.
\end{abstract}

Keywords: rhizome, assemblage, object encounters, race and racism, walking interview

Copyright: (C) 2019 Maureen A. Flint

This is an open access article distributed under the terms of the Creative Commons Attribution NonCommercial License, which permits unrestricted non-commercial use, distribution, and reproduction in any medium, provided the original author and source are credited.

Please reference as: Flint, M.A. (2019). Hawks, Robots, and Chalkings: Unexpected Object Encounters During Walking Interviews on a College Campus. Educational Research for Social Change, 8(1), 120-137. http://dx.doi.org/10.17159/2221-4070/2018/v8i1a8

\section{Introduction}

The hawk lingered with me. Long after the interview concluded, I couldn't shake the encounter and how it disrupted the walking interview I had been on with Kathleen (a pseudonym), a student in her second year of college. What did the hawk do to the interview? How did it entangle with us, even as we continued walking? How did the hawk affect the stories and narratives that Kathleen told on our 
journey across campus? In this paper, I explore the possibility for objects to generate dynamic and relational understandings of space and time in educational research through three object encounters that occurred during walking interviews with students. Specifically, the paper explores how the practice of walking makes possible a tangled series of contradictions, moments of rupture that open understandings between objects and place. For example, the unexpected violence of encountering a hawk feeding on a squirrel on the campus lawn produced not only an interruption in the motion of the interview but also emphasised the need for reflexive recognition for how extractive research processes are reproduced in qualitative research methods. Considering the pause engendered by a sculpture considered the entanglement of seemingly disparate discourses of the South, football, slavery, and racism. Bringing together these discourses leads to an assemblage of methodological considerations that would not have been possible in a sterile, confined room. The unexpected encounters of the walking interviews entangle objects and place.

Methodologically, walking inquiry affords an opportunity to engage in an active pedagogy of place and experience: the context of place with the participants in a research study (Irwin, 2006). Engaging with place through mobile methods complicates the often-deterministic narratives of higher education research on college student belonging (Harris, 2016). Through the process of walking interviews, the interview process is opened to encounter objects, unexpected events that stutter the production of sense making. Walking produces this stuttering in multiple ways, from the unexpected halting that encountering the hawk produced, to the slight pause of nostalgia engendered by a sculpture, to the change in direction and movement made possible by chalked markings. In this article, I lean into the unexpectedness of these encounters affirmatively, moving beyond what walking as method affords, and toward what it does. I begin by reviewing the literature of mobile methods, followed by an overview of the theoretical concepts of rhizomes and assemblages. Thinking with rhizomes and assemblages, I then turn to three object encounters that occurred during walking interviews on a university campus. Analysing these object encounters with rhizomes and assemblages suggests considerations for engaging with mobile methods as well as implications for considering the agency of objects in educational research.

\section{Becoming Mobile}

Mobile interview methods make possible different assemblages and connections, embodying and enacting an openness to different becomings (Burke, Lasczik Cutcher, Peterken, \& Potts, 2017). The sections that follow review the literature on mobile methods, first reviewing terms and definitions, then moving into what becoming mobile has made possible in educational research.

In research that has employed mobile interviews, there are a variety of terms that have been used to characterise mobile research methods. For example, Anderson (2004) used the term "bimble" to describe a process of walking or wandering, while Kuntz and Presnall (2012) used "intraview" to describe the enactment of Deleuzian positive difference, intervening in the isolated human subject through a relational and nonhierarchical encounter between the participant and researcher. The idea of "wandering" or "meandering" has been employed in research focused on the encounter of place (Burke et al., 2017; Cutcher, Rousell, \& Cutter-McKenzie, 2015; Kuntz \& Presnall, 2012), while other research has looked to the concept of the dérive from Debord (2006), where the path is determined by the pull of place and the environment (Burke et al., 2017; Morgan, 2016; Tuck \& McKenzie, 2015). However, the dérive has also been critiqued as perpetuating a hegemonic vision of a singular (usually masculine and able-bodied) subject who wanders without regard to inequities, justice, or implications for his meanderings (Springgay \& Truman, 2018). 
Thus, other researchers have developed terms that emphasise what walking produces, such as Irwin (2006), who used "currere," the active form of "curriculum," to emphasise inquiry over action while walking. Other researchers have used "go-alongs" or "shared walk" to describe a participant-led tour of a familiar environment, decentring the primacy of the interviewer (Bergeron, Paquette, \& Poullaouec-Gonidec, 2014; Carpiano, 2009; Myers, 2010). In addition, research that has incorporated artful methods has employed the terms "soundwalks" or "audiowalks" (Feinberg, 2016; Stevenson \& Holloway, 2017) and "artwalks" (O'Neill \& Perivolaris, 2014; Triggs, Irwin, \& Leggo, 2014) to emphasise the role other modalities play in producing place and encounters. Many of these studies also used the term, "walking interview" synonymously and alongside other terms (Bergeron et al., 2014; Carpiano, 2009; Cutcher et al., 2015; Feinberg, 2016; Jones \& Evans, 2012; Kuntz \& Presnall, 2012; Myers, 2010), or as the sole descriptor of their research method (Evans \& Jones, 2011; Harris, 2016; Jones, Bunce, Evans, Gibbs, \& Hein, 2008; Lynch \& Mannion, 2016). A common thread through these studies is the focus on walking-as-method and, following this, throughout this paper, I use "walking interview" as an umbrella for these terms.

Walking interviews have been used for a variety of methodological reasons, and implemented from a wide swath of disciplines. Walking offers an opportunity to create cartographies following the relations and connections between materialities (de Freitas, 2013; Martin \& Kamberlis, 2013). Walking as cartography enacts boundaries, terrains, landmarks, and orientations to place. Through the embodied act of traversing geographies and landscapes, walking attunes inquiry to the production of place. For example, Cutcher, Rousell, and Cutter-McKenzie's (2015) arts-based inquiry included a performative process of walking together, and separately, creating multimedia cartographies from their encounters to suggest the collaborative and affirmative potential of educational research. Additionally, I (Flint, 2018) explored how a walking encounter, represented through visual transcription, produced different cartographies of campus, connections between race, whiteness, history, and campus monuments. This is echoed in the artful inquiry of Irwin (2006), who described her walking currere as a spiritual and aesthetic excursion into the pedagogy of self, an inquiry in the "liminal messy spaces between the roles, activities, and sites of who I am professionally and personally" (p. 79). Walking, then, both makes possible different encounters with place and produces place through the act. New cartographies and geographies are mapped through the action of walking. This is exemplified in Myers' (2010) study, which included three artworks that explored the intersections of walking and place: a guided walking tour, an operatic MP3 audio walk, and a soundscape installation. Each of these installations offered different engagements with place through a multimodal walking experience, while also changing the way that participants produced and related to place. Myers suggested that the rhythm and movement of walking, as well as the relational act of walking with others, encourages an empathetic awareness and connection to place.

Other research studies have noted the capacity of walking interviews to draw participants to the details of place, the minutiae of everyday experiences and practices, or to recall knowledges of place (O'Neill \& Perivolaris, 2014). For example, in his research on environmental activists, Anderson (2004) found that wandering the site of environmental protests with the activists he was researching offered an opportunity to reconnect with the environment, accessing the relationship between people, place, and time. Winton (2016) employed walking interviews to elaborate on photographs taken by research participants, and found that the walking interview elicited different responses from participants. Through walking, details and aspects of photographs taken by participants (that were not mentioned when the photographs were described and discussed in a traditional interview setting) were expanded on.

Methodologically, walking produces the possibility for affirmative difference within the interview-a positive embrace of reading objects as complex and connected. Martin and Kamberlis (2013) argued 
that the act of walking shifted the interview from an archaeological dig that seeks negative difference to an emplaced and relational encounter, embracing affirmative difference. Affirmative difference, following Deleuze and Guattari (1987), considers difference as defined through additions: the logic of and or meanwhile. Affirmative difference embraces simultaneity, contradiction, and multiplicity-a layering sequence of difference. This is distinct from negative difference, where difference is defined by lack, or what is missing. For example, the act of walking involves a constant series of relations and embodied connections between participants, the researcher, and objects. These relations include physical movements (speeding up, slowing down, pausing, changing direction, continuing, leading) as well as discursive movements and relations (noticing, remarking, remembering). Through walking, these relational and embodied movements entangle and, to explore this entanglement, I seek theoretical concepts that embrace the connections between objects, bodies, and places.

\section{Theoretical Framework}

In this paper, I plug into two Deleuzoguattarian concepts, the rhizome and the assemblage, to guide my analysis of three object encounters that occurred during walking interviews. Deleuze and Guattari (1987) wrote: "There are no points or positions in a rhizome, such as those found in a structure, tree, or root. There are only lines" (p. 8). Rhizomes are oriented towards experimentation and differentiation, and are made up of many lines: lines of organisation and categorisation, lines that crack and break, lines that rupture and break away. As these lines form connections and relations, they create assemblages: "phenomena of relative slowness and viscosity ... acceleration and rupture ... lines and measurable speeds" (Deleuze \& Guattari, 1987, p. 4). The assemblage is rhizomatic and folding, a process of shaping and movement, weaving together unconnected bodies and materials. Nordstrom (2015) described the assemblage as "creating a multiplicity of being and knowing that does not relate back to the same or the one" (p. 170). Rhizomatic movements make up the map of the assemblage, which "must be produced, constructed . . . always detachable, connectable, reversible, modifiable, and has multiple entryways and exits of its own" (Deleuze \& Guattari, 1987, p. 21). The assemblage and the rhizome are coproductive: the assemblage is rhizomatic as the rhizome is an assemblage. Methodologically, the assemblage and the rhizome have been used throughout the process of inquiry. For example, Nordstrom (2015) described her data as a "Deleuzoguattarian assemblage," a loose and ever shifting, shaping, flowing grouping of words, people, ideas, objects, and etcetera; these "folding, fibrous, and connective rhizomatic data created beautiful lines of thought that refused categorization" (p. 167). Inquiry that thinks with rhizomes and assemblages, then, connects disparate encounters, moments, and objects through affirmative difference, embracing connections and relations.

Methodologically, my research project seeks practices that move with and embody the rhizome and assemblage through the process of inquiry and analysis. Embodying assemblages through research methods and practices makes possible different understandings of the research process. For example, walking embodies a rhizome by bringing together disparate and unrelated moments through movement, producing an assemblage. Simultaneously, assemblages become an analytic tool for exploring the rhizome produced through walking. Analytically, assemblages and rhizomes consider the "bodies, things, and abstractions that get caught up in social inquiry, including the events that are studied, the tools, models, and precepts of research, and the researchers themselves" (Fox \& Alldred, 2015 , p. 400). The assemblage opens research to inquire beyond what things are, to what they do. This includes the method of the walking interview as a practice that opens the event of the interview to the productions of place through unexpected encounters with objects. For example, my research began as an inquiry on college students' belonging in higher education. However, through the encounters that occurred during walking interviews, I became interested in the particular configuration of belonging, place, and history. Through walking, I began to consider the ways in which belonging might become differently in a particular context. More specifically, through encounters with 
objects (moments that stuttered and ruptured the course of walking interviews), I began to ask questions about how a university located in the Southeastern United States (a geographical location referred to as the Deep South or, by the participants in my study, as "the South") is produced in ways that both emphasise and solidify the history of slavery and racism in the United States (and the region and university specifically), at the same time as that history is put under erasure. Rhizomes and assemblages suggest how a walk that I take with a student is connected to a hawk, is connected to a slave cemetery, is connected to the closing of the iron plants in Birmingham, Alabama, is connected to college football, is connected to the experience of students of colour on campus and the reproduction of white supremacy on campus.

\section{Research Site}

The three object encounters this paper explores took place during walking interviews conducted for a pilot research project exploring college students' belonging on campus. We embarked on these walks in mid-November of the fall 2016 semester. Students who participated in the pilot study were first invited to participate in a focus group and then asked to participate in a walking interview. The walking interviews were intended to continue discussions that emerged during the focus groups as well as explore the nuances of individual students' navigations of belonging on campus. Walking inquiry in local or public spaces presents unique ethical challenges in that participants may be recognised or intercepted by others throughout the course of the interview. When reviewing the informed consent document with participants at the start of the walking interview, I confirmed that each student understood that confidentiality could not be ensured (because we would be walking in a public space). I also reiterated to participants that they were free to opt out of the walking interview at any time, and established that they were comfortable with me carrying a small audio recorder throughout the duration of our walk. However, like Harris (2016), I found that participants often introduced me to their friends or peers when we were intercepted, enthusiastically providing a brief description of the research study. Although seven students took part in this study, the three object encounters that this paper explores occurred during the walking interviews of Kathleen, a white female student who was in her second year of a music programme, and Ben, a white male student who was in his fourth and final year of an engineering programme.

The first object encounter, with Kathleen, is an abrupt and startling moment when we came across a hawk feeding on a squirrel on the campus lawn. The second encounter occurred with Ben, and is a moment when Ben's nostalgic connection to a sculpture that we walk past folds and connects with our conversation about the history of campus. The final encounter, which occurred later on the same walk with Ben, is a moment when we are pulled towards another part of campus through connections made by chalk markings on the sidewalk. I illustrate each moment with poetic transcriptions (Glesne, 1997, Öhlen, 2003) of the object encounters, followed by analysis and photographs taken by participants during our walking interviews, or shared after the interview. Throughout, I take up the theoretical concepts of the rhizome and assemblage enacting Deleuze and Guattari's (1987) urge to "always follow the rhizome by rupture; lengthen, prolong, and relay the line of flight; make it vary, until you have produced the most abstract and tortuous of lines" (p. 11). 


\section{Object 1: A Hawk}

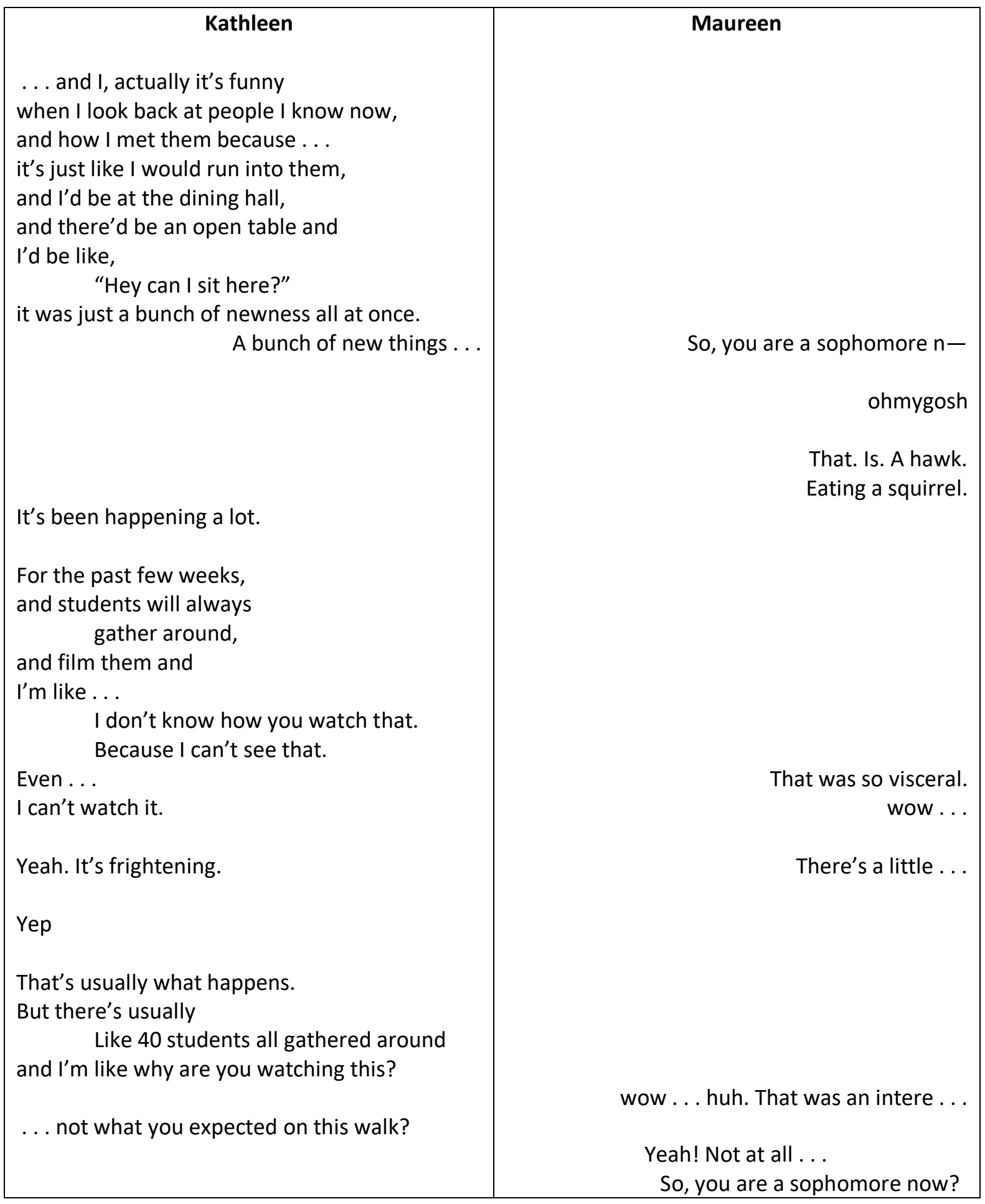


This moment with the hawk is a segment of data that would typically be discarded as unusable, an interruption, or an unfortunate disruption to the conversation of the interview. At this moment, Kathleen and I are just starting our walking interview, following a meandering sidewalk that bounds the west periphery of campus behind the business school. As we turn a corner to head towards the central part of campus, a sudden movement pulls us from the introductory talk of our interview and my question referring to her status as a second-year college student ("So, you're a sophomore now?"), and we both become aware of a large hawk, sitting on a patch of grass, disembowelling a squirrel. Our conversation spurts and stammers around this event, with Kathleen expressing indignation: "I don't know how you watch that, because I can't watch it," as I try to articulate what is happening, my words tripping over one another: "ohmygosh" emerges in a burst, followed by a series of stutterings - "that was so visceral ... wow ... there's a little." The unlikely intrusion of the bodies of the hawk and the squirrel disrupts the grooves and processes of the interview, interrupting our conversation, stopping our bodies, pulling us toward them. This interruption/stop/pull of the object/bodies of the hawk and squirrel affect Kathleen and me in a way that a retelling of the event in a traditional interview space would not make possible.

Even as this moment disrupted our talk during the interview-causing us both to pause and exclaim, the possibilities that our encounter with the feeding hawk produced were quickly overtaken by the function of the interview. This object encounter is bracketed by my statement, "So, you are a sophomore now?" continuing the course of the interview without pause despite (in spite) of the disruption. The interview parted momentarily and then picked up again as if the event had never happened. St. Pierre (2013) reflected that the work of researching, writing, and embodying the material-discursive rhizome in qualitative inquiry is difficult work. Engaging in qualitative inquiry methodology as a rhizomatic endeavour is a practice of constantly, consciously resisting thoughts of the essence of truth, reason, meaning, and being. The pull of traditional methodologies is so powerful, St. Pierre suggested, that "we can slip back into it with a single, telltale word" (2013, p. 655). This object encounter emphasises the powerful pull of the ways that traditional research methodologies and ideologies act on bodies. Even as Kathleen and I embarked on this walk to move beyond the boundaries of the static room, to create rhizomes through our movements across place and with objects, the function of the interview lingers as a strategy for data extraction (Kuntz, 2015). The pull of traditional research methodologies asserts that particular types of talk are "right" or "correct"-answers and narratives that we should follow along or pursue as opposed to others. At this moment, the pull of traditional research methodology echoes in the refrain of "So, you are a sophomore now?" a repeated statement that returns us to comfortable and known territories of experience and extraction, away from the disruption produced by the object.

As Kathleen and I stutter, unsure of how to respond to the hawk and squirrel, we are presented with the option of following the encounter as a vibrant object, opening a series of questions that would not have otherwise been possible. What is it about the hawk that draws the crowd of students? What is frightening about this moment? Why wasn't this what we expected in the context of the interview (or on campus)? This line of questions could have stopped our walk, pulled us towards the hawk and squirrel to watch and consider what else it made possible, what other assemblages it coproduced. Untangling this moment and the marks left on it by the pull of traditional research methodologies makes visible the danger of using mobile methods unreflectively. As detailed in the review of the literature using mobile methods, the entanglement with matter and place is often emphasised as the reason for incorporating mobile methods in educational research. Yet, as this moment illustrated, the vibrant possibilities and entanglements with objects that walking make possible can quickly become smoothed over, skipped past, reinstituted into the technicity and extraction of the very methods walking interviews seek to move beyond. 
The object of the hawk, and the series of questions and considerations it produced, reemerged in another phase of this research project. Several months later, another participant, Owen, shared a similar experience where she encountered a feeding hawk on the campus lawns. With Owen, the act of walking by a site on campus where she remembered often pausing to watch squirrels caused her to remember the event of a feeding hawk (although we established that it happened at a different time and location as the encounter that Kathleen and I had witnessed). Following her sharing of the story during her walking interview, Owen sent me a picture she had posted on social media of the event (Image 1). The two events - the encounter of the hawk with Kathleen, and the telling of Owen's experience encountering a similar event at a different place and time-echo each other. With Owen, the telling of the narrative was the event, one that was made possible through the walking interview, even as it did not fundamentally disrupt our talk. With Owen, the act of walking produced a remembering about the place we encountered, a sense of familiarity that then led, rhizomatically, to a story about a hawk. With Kathleen, even though the walking interview was framed as guided by and responsive to the objects and places we encountered, no discussion of how she felt about the hawk and squirrel followed the encounter, even as (and perhaps because of) its violence and disruptiveness. Owen's story lacked the vibrancy of my encounter with Kathleen in the telling yet, our entertaining of what it made possible, what the hawk did, led us to other conversations-about Owen's experience as a black student on a predominately white campus, about the exclusive culture of fraternal student organisations (fraternities and sororities) on campus. Specifically, Owen shared a story about visiting a white all-female social club (sorority) on campus for the first time, and her feelings of discomfort there. Deleuze and Guattari (1987) wrote that "unlike trees, or their roots, a rhizome connects any point to any other point, and its traits are not necessarily linked to traits of the same nature; it brings into play very different regimes of signs" (p. 21). Rhizomatically, Owen's stories about belonging and place as a student of colour on campus flowed from our talk about squirrels and hawks-unlikely narratives that nevertheless become entangled with the production of place and the assemblage of the university.

\section{Image 1: Hawk and Squirrel}

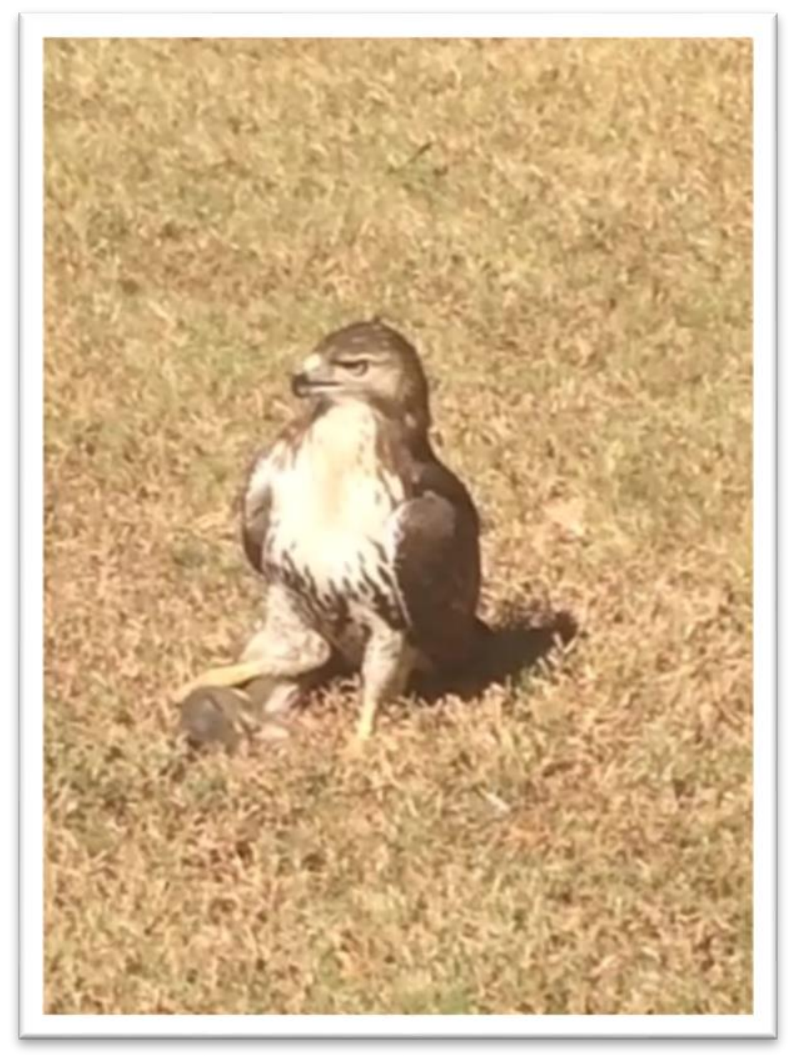




\section{Object 2: A Robot}

This second object encounter occurred while Ben and I were walking through a part of the campus that houses the College of Arts and Sciences. This area, known as Woods Quad, is a quiet, shady courtyard formed by four academic buildings: Woods, Clark, Garland, and Manly Halls. The wrought iron balconies of Woods Hall that look out onto the quad front studio spaces for art majors and a campus art gallery and Clark Hall, a graceful tiered and turreted brick building, hosts the dance studio and academic advising. Manly Hall is home to the Department of Gender and Race Studies and the Department of Religious Studies. Enfolding with the current contexts of place, Woods Quad is imbued with history and, specifically, the history of the American Civil War. Fought between 1861 and 1865, the American Civil War was fought between the Northern and Southern United States when a bloc of southern states seceded from the rest of the country over the right to own slaves. Built after the war, between 1867 and 1868, Woods Hall is constructed from the bricks of the buildings burned by the conquering northern federal forces. Woods derives its name from the first president of the university, Alva Woods, whose administration saw the first significant usage of enslaved labour on the campus. Manly Hall is named after the second university president, Reverend Basil Manly, who defended slavery on religious grounds and delivered the prayer at the inauguration of southern Confederate President, Jefferson Davis (Green, n.d.). And Garland Hall is named after the third president of the university, Landon Garland, who employed personal slaves during his administration before and during the American Civil War. In the context of this layered history, Ben reflected on how the university administration had handled racial tensions and the history of race on campus. As we passed a sculpture of a fallen robot in the grass, he lost his train of thought.

\begin{tabular}{|l|l|}
\hline \multicolumn{1}{|c|}{ Ben } \\
Despite being the football team that represents \\
the South. \\
Because you know football is integral \\
to the culture here. \\
The culture, \\
and one of the biggest and fastest growing \\
southern schools. \\
So, maybe that's how that conversation starts. \\
But I do think they're doing better than \\
I even realise. Like I heard from \\
uh one of the ... \\
uh, I love that little robot. \\
It's apparently some kind of allusion to Sloss \\
furnaces \\
$\begin{array}{l}\text { So, I always ... } \\
\text { but I lost my train of thought. }\end{array}$ \\
$\begin{array}{l}\text { Yeah, I mean I just think. } \\
\text { I mean there's such a chance to be stewards } \\
\text { for really the whole country. } \\
\text { Maybe, this is definitely coloured by } \\
\text { my experience growing up in the South } \\
\text { and feeling always like sort of on the fringes of } \\
\text { like society... }\end{array}$ \\
\hline
\end{tabular}


The sculpture that Ben referenced is titled, Goldie 1971 (see my photograph, Image 2), and it was created by Joe McCreary in 2009 to commemorate the history of Birmingham Alabama's Sloss Furnaces, as Ben alludes to in our conversation. The robot, as the iron factories, rests in the grass, invoking a quiet sense of dignified forfeiture, reluctantly succumbing to rust and antiquation. This moment produces a rhizome, a pull of materialities, zigzagging from the silent loomings of the buildings around us to the fallen robot, to the ideas that Ben references of the university's culture, football, and the South. Complicating this rhizome is Ben's personal involvements on campus, initiatives he has organised to confront and address the history of slavery and race on campus that is memorialised through building names. Following the connections and relations between these objects, Ben's answer to the complications resonated: "there's such a chance to be stewards for the whole country," which, he notes, is "maybe ... definitely coloured by my experience growing up in the South."

\section{Image 2: Robot Sculpture}

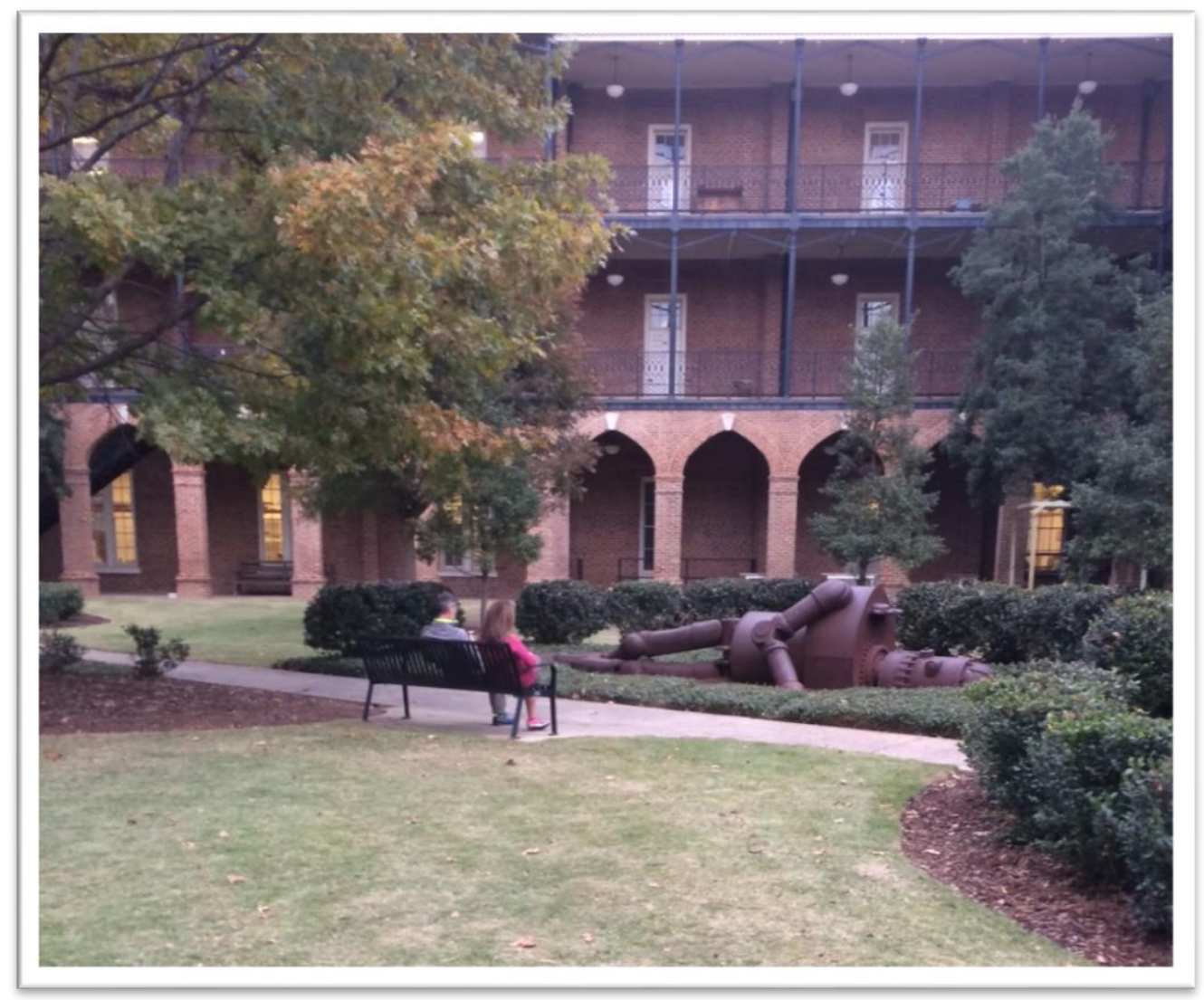

Exploring this moment methodologically, the encounter with the robot sculpture is enmeshed in an always-already-there tangle of bodies that enfold temporal and spatial scales. Ben's stutter, "I lost my train of thought," is a rupture in the course of the interview, a moment that temporarily makes the connections between spatial-temporal trajectories visible. His stutter is made possible not through the newness of the encounter, its abruptness, as with Kathleen, but through a sense of familiarity or nostalgia. Ben was familiar with the robot from other encounters on campus, and his pause engendered a serendipitous mirroring of the robot's meaning and artistic intent and his own description of the university as a steward for the region. Ben's pause makes possible a different assemblage of the complicated space of the South, as we are pulled towards the sculpture of the fallen rusted robot, one arm reaching slightly outwards as though it has just tried to push itself up off the ground, but has fallen back, exhausted. The robot and the assemblage of slavery, race, the South, football, iron factories, American Civil War, Sloss, Clark, Manly becomes differently through their entanglement. The robot transforms through the walking interview, as the fallen robot becomes the South, becomes Ben, "this is definitely coloured by my experience growing up in the South." This 
entanglement of Ben and the robot existed (exists) always-already before the walking interview. Yet, through the embodied act of walking, the assemblage of Ben and the robot vibrates and intersects with affirmative difference. Rhizomatic lines between objects produce different assemblages and connections. Representations stutter in this intersection, as the South is represented by the university, by football, the robot, by Ben, and this object encounter is an unfolding of layered assemblagesembodying the actualisation of spatial trajectories. For example, through this assemblage, we can imagine Ben becoming the robot, embodying the stewardship of the South as he discussed his exhaustion and despondency with efforts to make change on campus. De Certeau (1984) described the act of walking as, "situated in the act of a present (or of a time) and modified by the transformations caused by successive contexts" (p. 117). Walking, then, transforms understandings and meanings of place through encounters with objects. This object encounter emphasises the methodological possibility for mobile methods to embody the stuttering and stammerings of becoming, of affirmative difference.

\section{Object 3: Chalk}

The final data event occurred later in the same walking interview with Ben. Our walking took place in mid-November, just weeks after the 2016 United States presidential election of Donald Trump, and near the end of a several-months-long drought in the region. Ben and I were nearing the end of our walk, passing through a courtyard by a dining hall and a campus library when we paused by a series of chalk markings covering the ground. The chalk messages layered on each other, and interacted rhizomatically: a message supporting pro-life (anti-abortion) positions crossed out and amended to become pro-choice, an advertisement for Falsettos, a musical celebrating LGBTQ+ (lesbian, gay, bisexual, trans, queer) history next to a hastily scrawled "Blacks for Trump." Coming across these markings, Ben and I paused. As we paused, we read the messages aloud, tracing the temporalities of each, wondering which had come first, comparing handwritings to discern if messages had come from the same chalker. We wondered together about the contradicting and congealing messages the chalk objects communicated, and this wondering led to another object, a chalk marking that Ben had noticed on another walk, of an arrow directing passersby to the slave cemetery located behind the biology building on campus. 


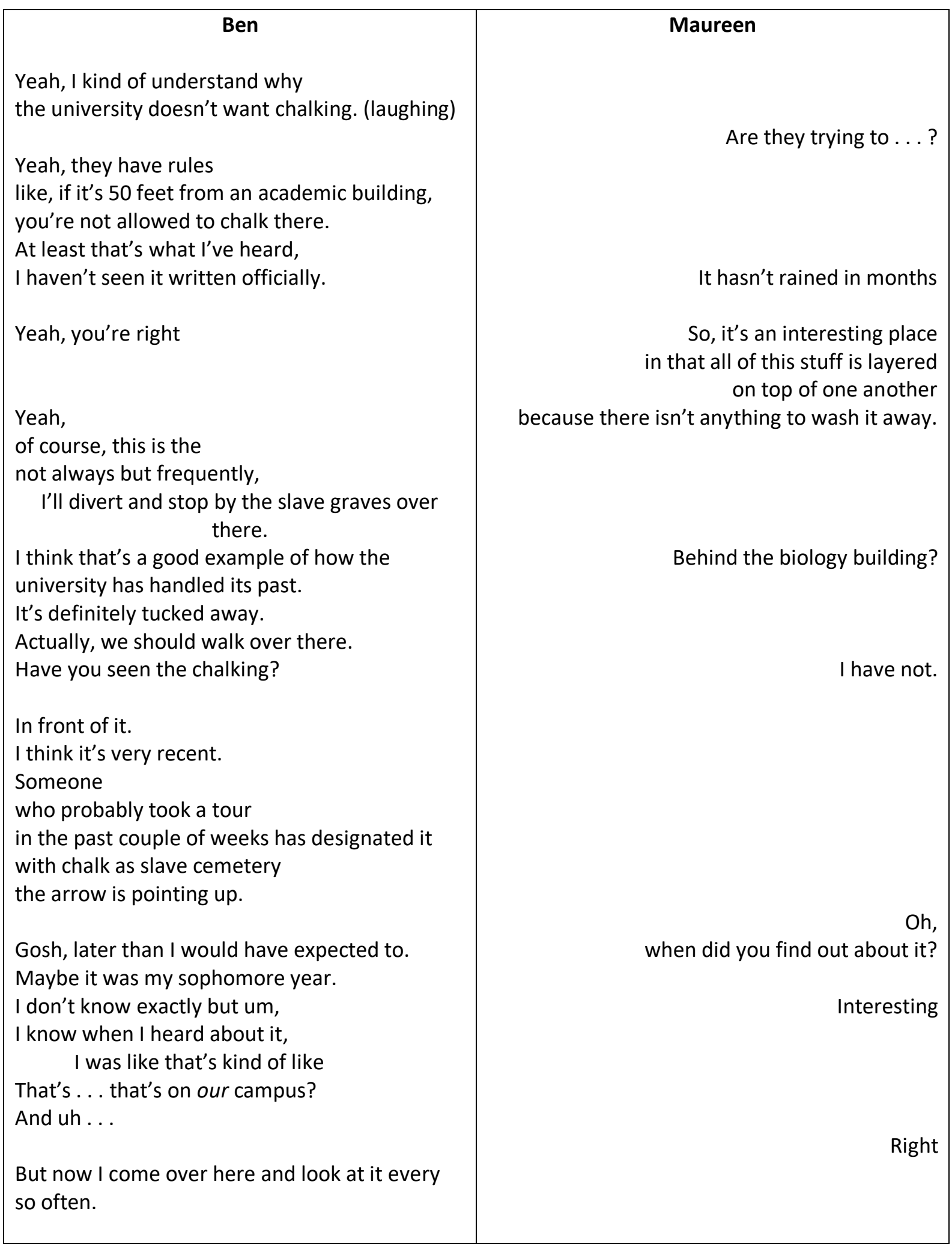

Here, again, Ben and I found ourselves pulled by objects, caught up in a different assemblage of place through our mobile engagement with the geography of campus. The assemblage of the political chalkings produced a series of connections, pulling us along with them - one set of chalkings pointing to another. At this moment, the object of the chalk markings entangle with the materiality of the drought that lingered on the campus. As I remark, "it hasn't rained in months," Ben is reminded of another chalking, in another space, a chalking that persists despite the ephemeral nature of chalk (due to the materiality of the drought). The drought and chalk produce rhizomatic connections. The chalk 
markings of "Blacks for Trump" becomes connected through our walk to a hastily scrawled directional arrow pointing passersby up a small, rarely traveled path that leads to a gated plot, marked as a slave cemetery by a small plaque and a wrought iron fence (see my photographs, Image 3 and Image 4). Both chalkings assert a magnetic pull through the connections and relations with the assemblage of campus. The slave cemetery chalking pulls bodies up the path, to read the apology plaque inserted by the faculty senate in 2004, to consider the lives of Jack Rudolph and Boysey Brown as part of the assemblage of the university (Green, n.d.). This in relation to the chalking, "Blacks for Trump," which pulled us toward it. "I wonder if a black person wrote that," Ben had mused aloud. The rhizome of chalk-blackness-place becomes differently with this consideration-

black hands gripping a piece of chalk to mark out a statement in favour of a political candidate (now president) who has been sued for racial discrimination, has posted numerous racist tweets, and is endorsed and supported by white supremacists (Blay, 2016). "Blacks for Trump" becomes differently in relation to the slave cemetery, just as the slave cemetery becomes differently in relation to "Blacks for Trump." This relationality zigzags across space and time, connecting the history of slavery and racism on campus to the 2016 presidential election, making possible considerations of how these events mirror and parallel each other. Put in relation to the black lives commodified by the university through the exploitation and violence of slavery, the relationality between the chalkings considers how black lives are currently commodified and exploited by higher education. Emplaced in the time of the walking interview, this intersection also makes visible the persistent devaluation of black lives in the United States, which galvanised the political conversation during the 2016 election season.

The chalkings of "slave cemetery" and "Blacks for Trump" create multiplicitious and layered assemblages, intersecting rhizomes that layer with the university as "the fastest growing southern school ... an opportunity to be stewards for the whole country." The contradiction of these relations vibrates at the intersection of the lines between stewardship, presidential candidates, and slavery. Simultaneously, as we're pulled towards the slave cemetery that is made visible through chalk, Ben notes, "it's a pretty good example of the university remembering things but it's not perfect," even as we are only pulled towards the cemetery because of a visual act of transgression from the narrative of stewardship, recruitment, and admissions. We might envision a student taking the liberty to mark the location of the slave cemetery differently than the faculty senate plaque, to pull passersby toward the tucked away plot as resistance or intervention in place. Temporally, this visual transgression becomes, again, in this specific space and time, a chalk arrow and marker that sits alongside and with the marker from the faculty senate placed in 2004, speaking back to the national election and discourses of white supremacy.

This rhizomatic line of white supremacy leads us to yet another assemblage, a rupturing of who the university is for: "that's on our campus?" Ben had remarked. Moore and Bell (2017) suggested that there is a symbiotic relationship between overt acts of racism on campuses and more subtle, colourblind racism, a relationship that serves to reproduce the space of higher education as white space, reinscribing and reinforcing white supremacy. For example, even as administrators denounce acts of racism, this denouncement erases other, more subtle forms of racism, (re)producing campus spaces as racist and perpetuating white supremacy. In this object encounter, even as Ben, a white student, is trying to remake the space of the campus differently through his activism with building names, his stories reproduce the space of the campus as white. Recruitment, stewardship, and admissions produce lines of whiteness that seek to preserve the hegemonic space of the campus. The cemetery becomes visible through the ephemeral, hastily drawn lines of chalk on a more prominent sidewalk. This happens even as Ben remarks that the plaque represents a good example of the university recognising the racial history of the campus, even as Ben remembers finding out about the slave cemetery "later than I would have expected to." The cemetery (and its assemblage of black lives, white supremacy, slave ownership, racism) is distanced from the place of campus: "that's on our campus?" 
The push and pull of objects that produce these contradicting and overlapping rhizomes and assemblages becomes possible through the embodied action of walking.

Image 3: Chalkings

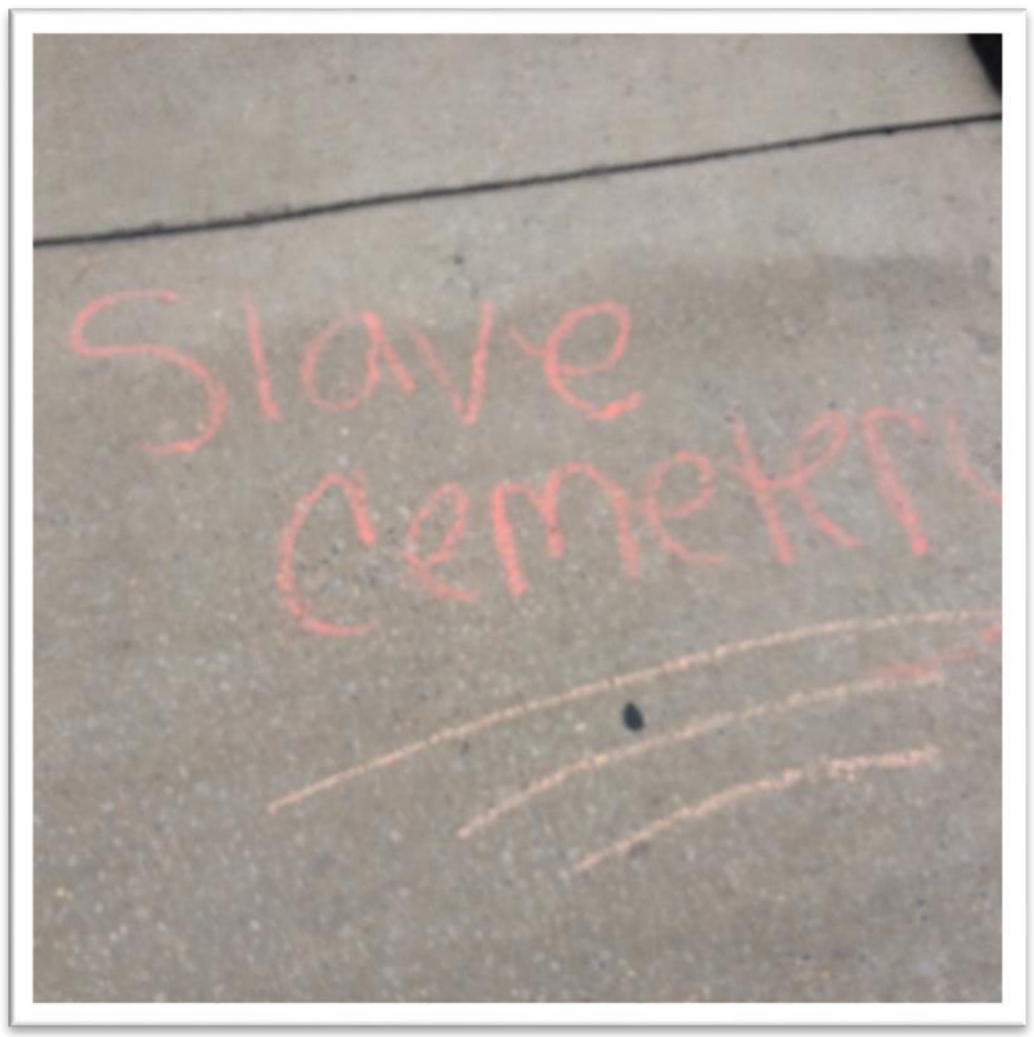

Image 4: Slave Cemetery

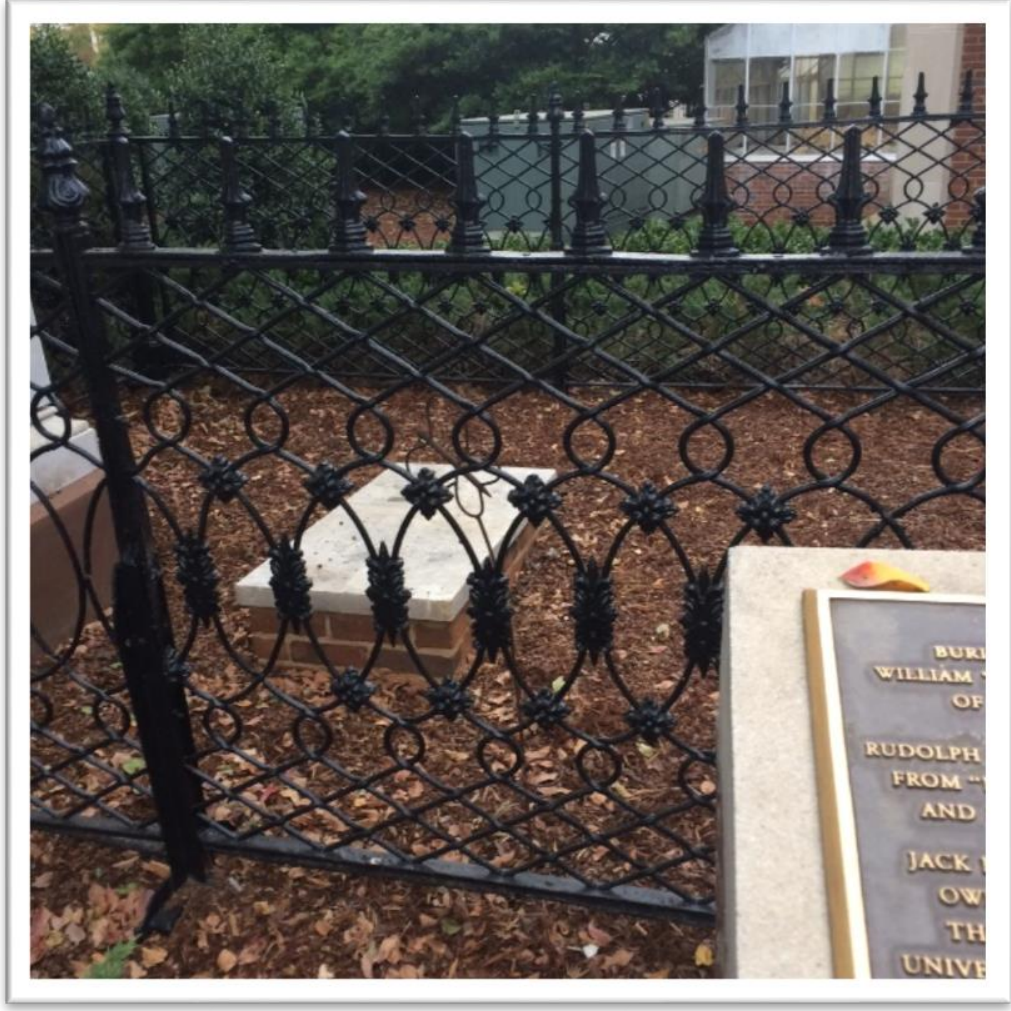




\section{The Unexpected}

My intent through this paper was to lean into encounters with objects made possible through walking interviews, moments where objects acted on the participants' and my body with agency, where the interview was produced differently. I sought to methodologically move beyond what walking inquiry is, to ask how walking produces inquiry. First, the unexpected violence of the hawk briefly and momentarily inserting itself into the interview talk suggests considerations for researchers embarking on mobile methods. A review of the literature illustrated that walking is often incorporated into research designs to encounter or elaborate on participants' engagement with place. Thus, researchers should consider how the theoretical grounding of their research might guide their response to unexpected interruptions. Considerations of how these interruptions produce the interview can challenge the pull of extractive approaches to research through an embrace of the unexpected and even absurd. In addition, walking as a method suggests ethical considerations for participant confidentiality and comfort with the method. Given that walking is a public act, researchers should emphasise that confidentiality cannot be ensured, and should discuss with participants how to approach possible interceptions or recognitions by peers. In this research project, I approached this by allowing participants to take the lead when we encountered their friends or peers, introducing me (or not) and describing the research project (or not) at their own comfort level. Additionally, what becomes possible by entertaining the questions interruptions produce was further illustrated through the object encounter with Owen, where entertaining her similar encounter with a hawk led her to share other stories about unexpected experiences on campus as a student of colour. With both Kathleen and Owen, the act of walking produced questions and considerations that became uniquely possible through the active encounter with objects and place.

In the second encounter, the entanglement of the robot sculpture, the South, football, Ben, slavery, and racism transformed how place was produced through the walking interview. The serendipitous encounter of a familiar sculpture that represented the struggling Southern iron economy produced a pause in our conversation, a pause that made visible multiple spatial and temporal scales - an alwaysalready-there tangle that offered imaginative reconceptualisations of how race is produced and maintained through spatial practices. The serendipity that becomes possible through walking inquiries produces new connections and relations. Through these connections, made possible through walking, researchers can consider how participants and places are co-implicated and entangled. The spatiotemporal connections walking engenders make visible the intersections of seemingly disparate objects. Disentangling contradictions in the production of place that walking makes visible, suggests implications for intervening in the reproduction of hegemonic narratives. Following work by black feminist authors such as Zora Neale Hurston's (1938/2008) anthropological inquiry, or Alice Walker's (1979) evocative telling of searching for Hurston's unmarked grave, walking inquiry incorporated alongside critical and postmodern theoretical orientations enacts affirmative difference through acknowledging perspectives that have been lost or suppressed. Acknowledging and retelling hidden stories remakes place through their telling-enacting affirmative difference and offering the possibility for place to be produced differently in the future.

Exploring these object encounters suggests ethical considerations for methodology that become possible through the walking interview. The spatial aspect of walking makes possible a tangled series of contradictions, moments of rupture between what objects do and become, and the material stories of place. Embracing the possibility that encounters with objects afford through walking embodies a search for stammerings and rupturings of sense to "confront experience as questionable, as problematic, and as incomplete-rather than as a foundation for truth" (Jackson \& Mazzei, 2008, p. 304). Examining what object encounters produce emphasises the importance of the researcher's awareness and intention behind the cuts and connections made through methodology. Walking produces numerous entry points into this tangle, an infinite number of points to enter the map and a 
multitude of connections and combinations of assemblages that offer the possibility to intervene in, and reproduce, spaces in more socially just and equitable ways.

\section{References}

Anderson, J. (2004). Talking whilst walking: A geographical archaeology of knowledge. Area, 36(3), 254-261.

Bergeron, J., Paquette, S., \& Poullaouec-Gonidec, P. (2014). Uncovering landscape values and microgeographies of meanings with the go-along method. Landscape and Urban Planning, 122, 108121. https://doi.org/10.1016/j.landurbplan.2013.11.009

Blay, Z. (2016, March 11). 12 reasons Donald Trump would not be great for "the Blacks." Huffington Post. Retrieved from http://www.huffingtonpost.com/entry/8-reasons-donald-trump-would-notbe-great-for-the-blacks us 56e0729fe4b065e2e3d47e82

Burke, G., Lasczik Cutcher, A., Peterken, C., \& Potts, M. (2017). Moments of (aha!) walking and encounter: Fluid intersections with place. International Journal of Education Through Art, 13(1), $111-122$.

Carpiano, R. (2009). Come take a walk with me: The "go-along" interview as a novel method for studying the implications of place for health and well-being. Health \& Place, 15, 263-272.

Cutcher, A., Rousell, D., \& Cutter-McKenzie, A. (2015). Findings, windings and entwinings: Cartographies of collaborative walking and encounter. International Journal of Education Through Art, 11(3), 449-548.

Debord, G. (2006). Theory of the dérive. In K. Knabb (Ed. \& Trans.), Situationist international anthology (revised \& expanded, pp. 62-66). Berkeley, USA: Bureau of Public Secrets.

de Certeau, M. (1984). The practice of everyday life (S. Rendall, Trans.). Berkeley, USA: University of California Press.

de Freitas, E. (2013). Mapping the materiality of classroom discourse: Expression and content in school mathematics. In D. Masny (Ed.), Cartographies of becoming in education: A Deleuze-Guattari perspective (pp. 127-140). Rotterdam, Netherlands: Sense.

Deleuze, G., \& Guattari, F. (1987). A thousand plateaus: Capitalism and schizophrenia (B. Massumi, Trans.). Minneapolis, USA: University of Minnesota Press.

Evans, J., \& Jones, P. (2011). The walking interview: Methodology, mobility and place. Applied Geography, 31, 849-858. Retrieved from https://doi.org/10.1016/j.apgeog.2010.09.005

Feinberg, P. P. (2016). Towards a walking-based pedagogy. Journal of the Canadian Association for Curriculum Studies, 14(1), 147-165.

Flint, M. (2018). Ruptures and reproductions: A walking encounter with a campus tour and a Confederate monument. Cultural Studies $\leftrightarrow$ Critical Methodologies, 1-14. Retrieved from https://doi.org/10.1177/1532708618809136

Fox, N. J., \& Alldred, P. (2015). New materialist social inquiry: Designs, methods and the researchassemblage. International Journal of Social Research Methodology, 18(4), 399-414.

Glesne, C. (1997). That rare feeling: Re-presenting research through poetic transcription. Qualitative Inquiry, 3(2), 202-221.

Green, H. (n.d.). Hallowed grounds: Race, slavery, and the university. The University of Alabama. Retrieved from http://hgreen.people.ua.edu/uploads/6/3/7/7/63777429/hallowed grounds printableguide.pdf 
Harris, J. (2016). Utilizing the walking interview to explore campus climate for students of color. Journal of Student Affairs Research and Practice, 53(4), 365-377.

Hurston, Z. N. (2008). Tell my horse: Voodoo and life in Haiti and Jamaica. New York, USA: Harper. (Original work published 1938)

Irwin, R. L. (2006). Walking to create an aesthetic and spiritual currere. Visual Arts Research, 32(1), 75-82.

Jackson, A. Y., \& Mazzei, L. (2008). Experience and "I" in autoethnography: A deconstruction. International Review of Qualitative Research, 1(3), 299-318.

Jones, P., Bunce, G., Evans, J., Gibbs, H., \& Hein, J. R. (2008). Exploring space and place with walking interviews. Journal of Research Practice, 4(2), 1-9.

Jones, P., \& Evans, J. (2012). Rescue geography: Place making, affect and regeneration. Urban Studies, 49(11), 2315-2330.

Kuntz, A. M. (2015). The responsible methodologist: Inquiry, truth-telling, and social justice (1st ed.). Walnut Creek, USA: Routledge.

Kuntz, A. M., \& Presnall, M. M. (2012). Wandering the tactical: From interview to intraview. Qualitative Inquiry, 18(9), 732-744.

Lynch, J., \& Mannion, G. (2016). Enacting a place-responsive research methodology: Walking interviews with educators. Journal of Adventure in Education, 16(4), 330-345.

Martin, A. D., \& Kamberlis, G. (2013). Mapping not tracing: Qualitative educational research with political teeth. International Journal of Qualitative Studies in Education, 26(6), 668-679.

Moore, W. L., \& Bell, J. M. (2017). The right to be racist in college: Racist speech, white institutional space, and the First Amendment. Law and Policy, 39(2), 99-120.

Morgan, C. (2016). Walking studies, the Eastern townships, and Williams S. Messier's Dixie. Nottingham French Studies, 55(2), 224-238.

Myers, M. (2010). Walk with me, talk with me: The art of conversive way-finding. Visual Studies, 25(1), 59-68.

Nordstrom, S. N. (2015). A data assemblage. International Journal of Qualitative Research, 8(2), 166193.

Öhlen, J. (2003). Evocation of meaning through poetic condensation of narratives in empirical phenomenological inquiry into human suffering. Qualitative Health Research, 13(4), 557-566.

O'Neill, M., \& Perivolaris, J. (2014). A sense of belonging: Walking with Thaer through migration, memories and space. Crossings: Journal of Migration and Culture, 5(2/3), 327-338.

Springgay, S., \& Truman, S. E. (2018). Walking methodologies in a more-than-human world: WalkingLab. Abingdon, UK: Routledge.

Stevenson, A., \& Holloway, J. (2017). Getting participants' voices heard: Using mobile, participant led, sound-based methods to explore place-making. Area, 49(1), 85-93.

St. Pierre, E. A. (2013). The posts continue: Becoming. International Journal of Qualitative Studies in Education, 26(6), 646-657.

Triggs, V., Irwin, R. L., \& Leggo, C. (2014). Walking art: Sustaining ourselves as arts educators. Visual Inquiry, 3(1), 21-34. Retrieved from https://doi.org/10.1386/vi.3.1.21 1

Tuck, E., \& McKenzie, M. (2015). Place in research: Theory, methodology, and methods. New York, USA: Routledge. 
Walker, A. (1979). Looking for Zora. In Z. N. Hurston, I love myself when I am laughing and then again when I am looking mean \& impressive (1st edition, pp. 297-313). New York, USA: Feminist Press.

Winton, A. (2016). Using photography as a creative, collaborative research tool. The Qualitative Report, 21(2), 428-449. 